\title{
Reformulation of the Integrated Master in Mechanical Engineering (MIEM) at FEUP in Two Cycles of Studies (Bachelor and Master)
}

\begin{abstract}
L. F. M. da Silva ${ }^{1}$, Jorge Seabra ${ }^{2}$, António M. Lopes $^{3}$
${ }^{1}$ Department of Mechanical Engineering, Faculty of Engineering, University of Porto, Rua Dr. Roberto Frias, 4200-465 Porto, Portugal; INEGI-Institute of Science and Innovation in Mechanical and Industrial Engineering (lucas@fe.up.pt) ORCID 0000-0003-3272-4591; ${ }^{2}$ Department of Mechanical Engineering, Faculty of Engineering, University of Porto, Rua Dr. Roberto Frias, 4200-465 Porto, Portugal; INEGI-Institute of Science and Innovation in Mechanical and Industrial Engineering (jseabra@fe.up.pt) ORCID 0000-0003-1919-0003; ${ }^{3}$ Department of Mechanical Engineering, Faculty of Engineering, University of Porto, Rua Dr. Roberto Frias, 4200-465 Porto, Portugal; INEGI-Institute of Science and Innovation in Mechanical and Industrial Engineering (aml@fe.up.pt) ORCID 0000-0001-7359-4370
\end{abstract}

\begin{abstract}
This paper presents the reformulation of the Integrated Master in Mechanical Engineering (MIEM) at the Faculty of Engineering of the University of Porto (FEUP) in two independent degrees (bachelor and master). The design of the new cycles of studies, triggered by decision of the Portuguese Government, followed the FEUP's guidelines and led to a solution close to the one adopted by the existing integrated master. Therefore, the well-known "FEUP Mechanical Engineering product" is maintained, in general, since it is widely accepted in the job market, and improved by correcting some MIEM's shortcomings. The bachelor is a non-professional degree of preparation to the master. It is clearly distinct from the cycles of studies thought at the polytechnic institutions, providing a broader scientific background, and not including design skills and dissertation. The master is a demanding degree, with innovative content and incorporating the value added by the excellence of the scientific research carried out at the Department of Mechanical Engineering. It is aligned with the needs of the industry, being different from other master degrees in the same area offered in Portugal, and designed to attract students from abroad. A SWOT analysis performed both for the bachelor and the master shows the potential of the two new cycles of studies.
\end{abstract}

Author Keywords. Higher Education, Mechanical Engineering, Bachelor and Master Degrees, Programme Design.

Type: Research Article

๑ Open Access $[\mathbf{6}$ Peer Reviewed $@$ (i) CC BY

\section{Introduction}

The origins of the Integrated Master in Mechanical Engineering (MIEM) at the Faculty of Engineering of the University of Porto (FEUP) go back to the reorganization of the Polytechnic Academy in 1885, which led to the establishment of the academic degrees in Engineering of Public Works, Mines and Industry. The Mechanical Engineering degree became autonomous in 1915 and FEUP was created in 1926. FEUP adopted a departmental structure in 1974, including a Department of Mechanical Engineering (DEMec), and took the responsibility for the five years of the Mechanical Engineering degree. The changes to higher education in Europe (Bologna process) were adopted in 2006/2007 (Wächter 2004; Heitmann 2005; Teixeira, Ferreira da Silva, and Flores 2007). Thus, the Mechanical Engineering degree at FEUP became a cycle of studies (CS) combining a first and a second CS degrees, specifically the 
bachelor ( 3 years) and master ( 2 years), respectively, into a single 5-year CS designated by MIEM. The most recent reformulation of the MIEM programme took place in 2014/2015. Currently, MIEM is organized in 10 semesters (www.fe.up.pt). At the end of the sixth semester (end of first CS) the students have acquired a solid base education, not only comprising the essential scientific and engineering skills, but also a broad, fundamental, non-specialized knowledge in several domains of Mechanical Engineering. This first CS is intended to provide the necessary background for allowing mobility to, and from, other national and European higher education institutions. After concluding the second CS, the MIEM graduates have gained an advanced level of education in Mechanical Engineering, focusing in one of five Specialization Areas, specifically Automation, Design and Manufacturing, Industrial Management, Mechanical Project and Construction, and Thermal Energy. As such, in the first four semesters, the MIEM programme allows students to acquire fundamental scientific knowledge of mathematics, physics, materials, drawing and basic engineering sciences. At the end of the seventh semester, the students have acquired extensive knowledge on fundamental subjects in the field of Mechanical Engineering. In the eighth semester, the students have learnt basic and detailed machine design, including different kinds of mechanical systems, and are ready to start their Specialization Area. Then, during the last two semesters, the students assimilate the multiple skills acquired along the MIEM programme, by carrying out a dissertation thesis.

The Portuguese Government took the decision in 2019 to separate the integrated masters' degrees in two distinct CS: the bachelor (first CS) and the master (second CS). The duration of each CS had to be decided by the higher education institutions. The students' access to the bachelor had to continue through the already existing national competition. The rules for the students to access the master CS, both during the transition phase and afterwards had to be decided. The rationale for the change was to make the Portuguese higher education system more in line with the European practice and, therefore, to facilitate the mobility of students between European higher institutions. The reformulation had to be implemented in September 2021.

The reorganization of the MIEM, followed the FEUP's guiding principles and the models in practice in many recognized European institutions, aiming to maintain the training of the "FEUP Mechanical Engineer" with duration of 5 years. The main idea was to preserve a "product" that was indeed competitive and well accepted by the job market. Nevertheless, the redesign of the MIEM in two new CS was grabbed as an opportunity to overcome the MIEM's shortcomings pointed out by leading employers, accreditation agencies and students. In this paper, the process behind the reformulation of MIEM is described, the main options are justified and the layout achieved is presented. Therefore, the rest of the paper is organized as follows. Section 2 discusses in a broad sense the advantages and disadvantages of implementing a professional vs. non-professional bachelor degree. Section 3 introduces the main FEUP's guidelines that define the framework of the integrated masters' reformulation. Section 4 details the restructuration of MIEM in two independent CS. Sections 5 and 6 present the new bachelor and master CS in Mechanical Engineering. Finally, Section 7 summarizes the main conclusions.

\section{Professional vs. Non-Professional Bachelor Degree}

The first question that arises when splitting an engineering integrated master in first and second CS is whether the first CS is sufficient to exercise the profession of engineer (Palmer 2004; Shamshina 2014; Choe et al. 2019). In this regards, the Portuguese Government decision 
of splitting the engineering integrated masters and, at the same time, maintaining the integrated master CS in other areas, as medicine, showed that the bachelor may be considered sufficient to perform some engineering tasks in a professional context. On the other hand, the Portuguese engineers' professional association ("Ordem dos Engenheiros") provides for two levels of professionalization of engineers, the first level being compatible with the bachelor and the second level corresponding to the master degree. The first level engineers are commonly referred to as technical engineers, with polytechnic higher education schools being the main trainers of these professionals.

When implementing a two CS based structure, it must be expected that an amount of students with a bachelor degree will consider leaving the university to start a professional career. Therefore, this issue must be considered in the reformulation of the integrated masters. Two options emerge when designing a new outfit: considering a clearly professional first CS, or conceiving a first CS that is limited in terms of skills and, thus, restricts the departure of bachelor graduates to companies. Any alternative will have a profound impact on the way FEUP works both in terms of education and funding. Moreover, the master and doctoral CS will be conditioned by the decision that is chosen.

\subsection{Professional degree}

Splitting the integrated masters in two $3+2$-year CS would probably be the easier way of implementing the desired reformulation. In this case, the main advantage of a professional bachelor degree is that graduates are prepared for the job market after just 3 years, thus, saving resources. Moreover, a professional first CS has the potential of attracting a broad range of students interested in engineering (those who want to be awarded only with the first CS plus those who are also interested in continuing to the second CS). The main disadvantage is that many engineering students may move to the job marked at the end of the bachelor, since they will have the necessary skills, and, therefore, become unavailable for enrolling in the master.

An effective professional bachelor in engineering must include design expertise and dissertation. However, in a 3-year CS, the two components seem impossible to coexist with a strong and extensive training in basic sciences, which is a distinctive characteristic of all CS at FEUP. On the other hand, to be really competitive in the job market, FEUP's CS must be clearly different from those offered by the polytechnic institutions. Therefore, FEUP's professional bachelors would need to last between 3.5 and 4 years. As the Portuguese legislation allows first CS to have from 180 up to 240 ECTS (European Credit Transfer System), it would be possible to design a bachelor degree fulfilling the required goals. The second CS must have between 60 and 120 ECTS. Thus, to keep a total of 5 years for both first and second CS, one option could be to have a bachelor with 3.5 and a master with 1.5 years.

Viewing the reformulation of the integrated masters as an opportunity to go beyond the 5year restriction, possible in the light of the legislation, another option could be to extend the total duration of the new CS. One hypothesis could be designing a 4-year first CS and a 1.5year second CS. This structure, could provide the FEUP's bachelors with basic sciences expertise and technical skills more advanced than those offered by the polytechnic schools and, therefore, much more competitive. Moreover, FEUP would keep all students for at least 4 years. This solution would be very comfortable for the economic sustainability of the CS. However, it would imply profound changes in the definition of the contents of the new CS. Another risk associated with this solution would be that FEUP could be seen as a professional university similar to the polytechnic institutions and not as a research university. 


\subsection{Non-professional degree}

A non-professional bachelor would allow designing the new CS with a structure very close to the adopted in the existing integrated masters. Basically, it would be only a matter of breaking the current CS in two distinct CS at the end of the third year. The main advantage of this minimal approach would be to keep almost unchanged a "product" - the "FEUP integrated master" - that is competitive and satisfies the job market. However, despite being the simplest solution to follow, the risk of losing students either to other universities or to the industry after they conclude their first CS is not negligible. Measures to attract students from other universities and countries could mitigate the issue, but so far students from abroad enrolling FEUP's CS revealed many technical gaps that have posed difficulties in their academic success. On the other hand, the current structure of the integrated masters with a 3-year first CS without design skills nor dissertation (clearly not-professional) and a 2-year master degree, yields the risk of students to start a career in the industry at the end of the first CS with insufficient preparation, which would give bad image to FEUP's training. The longer the first $\mathrm{CS}$, the higher is the risk of students to leave FEUP towards the job marked, because the training is more complete. A possibility not foreseen in the law, but which would reduce the issue of losing students to near zero, would be to have the first and second CS with 2 and 3 years, respectively. In this case, the first CS could be seen as a preparatory CS, similarly to what happens in the French system of large engineering schools.

\section{FEUP's Guidelines}

The University of Porto (UP) and FEUP have the responsibility of training engineers of excellence, who are fundamental agents for the transformation of the society. Challenged to reformulate its integrated master CS, FEUP decided to take the opportunity to reinforce the strengths and to correct the shortcomings of all CS, adapting them to the demands of the modern society, undergoing deep and fast transformations. In that line of thought, FEUP established the basic assumptions for the transition from the existing 5-year integrated master degrees to new $3+2$-year CS. These are:

- Fostering the excellence of a solid scientific education in the first CS, through the reinforcement of transversal components in Engineering Sciences (Mesquita et al. 2009), and deepening the specific scientific areas of the CS;

- Increasing the level of pro-activity of the undergraduate students, promoting the active search for opportunities to develop Transversal Skills for Engineering (Jimenez et al. 2015) (CTEs) in areas not directly related to their CS;

- Promoting opportunities for transversal training in Social and Human Sciences, by offering CTEs to be held in various Organic Units of the University of Porto (UP);

- Providing the students at the end of the first CS contact with the professional reality, through the implementation of an integrating project (Fink 1999) in the area of their CS or through performing an internship in a company or in a R\&D Unit;

- Promoting the recruitment of the most promising students for the master CS, regardless of the educational institution of origin;

- Fostering the excellence of the graduates in Engineering, deepening the transversal training in the fundamental scientific areas of the master CS;

- Increasing the connection between the master CS and the companies, through the effective participation of students in solving real-world problems and challenges, and by increasing the number of dissertations in firms or in R\&D Units; 
- Reinforcing the complementarity between transversal education in Engineering and areas of advanced knowledge available at R\&D Units and Interface Institutes, for the benefit of students in the master CS (Sun and Xue 2010).

In the reformulation of FEUP's integrated master degrees, a non-professional bachelor was assumed, contrary to what is practiced at the polytechnic higher education institutions. This means that the bachelor does not include the skills of conception and design, focusing on a strong theoretical and scientific training. The first level CS offered by FEUP should be seen as a preparation for the master and not as technical CS designed to train engineers that are ready to enter in the job market. The most technological part of the training of the FEUP engineer is concentrated in the second level CS. The bachelor can be understood as a scientific CS when compared with the CS offered by the polytechnic schools.

\section{Reformulation of the Integrated Master in Mechanical Engineering}

The reformulation of MIEM in a bachelor (LiEM), with 6 semesters, and a master (M.EM), with 4 semesters, in Mechanical Engineering, was handled in the framework decided by FEUP. A structure based on $3+2$ years was adopted for the new CS, thus, maintaining the basis of the "FEUP Mechanical Engineering product" that has proven effective in the job market. The best practices in European institutions were followed, while incorporating measures to overcome MIEM's weaknesses pointed out by top companies, accreditation entities and students. As such, the new LiEM and M.EM emerged as a renewed and stronger "product".

\subsection{Reference universities}

The CS of several reference European universities, such as the Polytechnic Universities of Turin and Milan, the Technical University of Munich, the EPF of Lausanne, the KTH of Stockholm, the ETH of Zurich, and the Universities of Aalborg and Leuven were analyzed. All institutions offer first and second CS with 3 and 2 years, and 180 and 120 ECTS, respectively. Thus, their bachelor and master CS have duration and structure similar those of LiEM and M.EM. This corresponds, on the one hand, to broadband first CS, non-professional and providing solid scientific bases. On the other hand, the second CS offer training of high technical-scientific density, linked to industry and research activities, in the various areas of Mechanical Engineering (offering various specialization areas and optional CU). This leads to learning objectives similar to those of LiEM and M.EM, which will facilitate the mobility of students within the European area.

Most students who complete the first CS in the aforementioned institutions enroll in the second CS, because a "complete engineer" in the countries of such universities is seen as a professional owning a master degree and not just a bachelor. In those countries, there are also engineers with a first CS, but these are trained in other schools that are more professional-oriented, like the Portuguese polytechnic institutions.

There are also European prominent universities that do not adopt the $3+2$ year scheme, such as the Universities of Aachen, TU Delft and the Polytechnic of Barcelona, offering instead first/second CS of $7 / 3,6 / 3$ and $8 / 4$ semesters, respectively. Still, at the Polytechnic University of Barcelona, the structure of the master degree is also identical to that of M.EM.

In the English universities, the scheme adopted is substantially different, with the existence of "MEng" CS, which are similar to 4-year integrated masters.

\subsection{Survey of local companies, accreditation entities and students}

The top 10 MIEM employers were consulted about the weaknesses and strengths of their FEUP Mechanical Engineers. Students' opinions and the recommendations of the "Ordem dos 
Engenheiros" and A3ES accreditation entities were collected during the process of preparing the new LiEM and M.EM. The results showed clearly that the key advantages of MIEM were its high theoretical basis, broad coverage of various scientific areas and multidisciplinarity. Moreover, MIEM graduates revealed good in transversal skills, such as dedication, commitment and rigor.

The inquiries also pointed out weaknesses, namely poor articulation between theoretical and practical skills, insufficient capabilities in computing programming, in management and in some technical areas, as marketing, maintenance, quality, environment and security, and in a number of transversal skills, as autonomy, leadership, creativity, proactivity, English, communication, and flexibility.

The new CS should pay attention to several emerging areas, as automation and control, coatings, acoustics, 3D printing, electric motors, integrated product design, renewable energies, CAM, robotics, composite materials, planning and management, Industry 4.0, data analytics, nanomaterials, nanotechnology, and biomechanics.

\subsection{Research areas at DEMec}

Most LiEM and M.EM teachers are integrated in R\&D Units based at the Institute of Science and Innovation in Mechanical and Industrial Engineering (INEGI) and the Institute for Systems and Computer Engineering Technology and Science (INESC TEC). Therefore, they carry out leading research in many areas of Mechanical Engineering and can transfer to the LiEM and M.EM the excellence of their R\&D, through involving the students in small works linked to ongoing projects or through the UCs of the CS.

Examples of research areas where the LiEM and M.EM's teachers are involved are structural composites, biomechanics, tribology, computational mechanics (solids and fluids), fatigue, maintenance, vibrations, experimental mechanics, renewable energies, building thermals, advanced bonding processes, simulation of technological processes, additive manufacturing, robotics, machine design, signal processing, optimization methods, and visualization methods. In terms of development, innovation and technology transfer, the main markets and sectors are energy and environment, metalworking, equipment goods, automobile and transport, space, aeronautics and defense, sea economy, services and health.

\subsection{Guidelines followed}

The reformulation of the MIEM aimed to maintain the training of the "FEUP Mechanical Engineer" with duration of 5 years, preserving a "product" that is definitely competitive and meets the companies' expectations.

The LiEM should be a 3-year non-professional CS, thus, not including design skills or dissertation. It should be regarded as a "preparation" for the M.EM. The LiEM should offer cross skills training (e.g., 12-hour short training UCs of 1.5 ECTS, activities for students focusing on soft skills training, multidisciplinary projects involving students' participation in multiple UP Organic Units), reinforce the computational and experimental activities, and include an Integrating Project (e.g., solving companies' "real problem", participating in a multidisciplinary projects in relevant areas, conducting internship in a business environment or in a R\&D Unit). The M.EM should be a CS differenced from others offered by Portuguese higher education institutions. It should propose a number of specialization areas that allows teachers to work with groups of students that are compatible with laboratory classes and encourage good interaction student/teacher. The technical and scientific content of the specializations should be designed to meet the needs of the industry. In particular, the area of transports (especially aeronautics) should be reinforced, due to the country's commitment in this area and the 
attraction it generates in engineer CS candidates. A transversal specialization (General Mechanical Engineering) should be included, since in many cases the industry needs professionals with broad knowledge. It is a common practice in many reference universities and pleases many students. This specialization should be essentially made up of CUs collected from the other specializations of the M.EM.

Typically, the students' education evolves from the CUs of basic sciences, at the first level CS, towards more professional UCs, at the second level CS. Therefore, the teaching/learning methodologies in the CUs of LiEM should benefit the students/teachers' proximity and supervision, while promoting the development of critical sense, autonomous study capacity and the development of group work skills. For the M.EM, the teaching/learning methods should have very applied nature, favoring the autonomy of the students. The typology of the classes and teaching/learning methodologies (e.g., exposure, problem solving, case study analysis, individual/group project-based teaching/learning, etc.) of each CU should be tailored to its objectives (e.g., knowledge, understanding, application, analysis, etc.).

Young fellows should be involved in teaching activities, namely in practical classes, since they are very close to the students and will promote a dynamic learning. More 3-year contracts (i.e., that last as much as a PhD) should be made to provide more stability. This would also be a good way to pass know-how from the older to the younger teachers. The senior teacher should be responsible for the theoretical classes.

All guide lines should contribute to improve both the approval/enrolled ratios on the UCs and the students' scores at the end of their CS.

\section{The Bachelor (LiEM)}

The LiEM is structured in 6 semesters, comprising a total of 180 ECTS. The approval in all CUs of the LiEM programme awards the students with the bachelor degree in Mechanical Engineering.

\subsection{LiEM organization}

Figure 1 and Figure 2 illustrate the LiEM layout, showing the CUs, their scientific area, and the main topics they covered. The CUs are distributed along 6 semesters, with 5 or 6 CUs per semester. The sixth $\mathrm{CU}$ is in the area of Personal development and transversal skills. The number of contact hours per week is about 20.

The ECTS of each CU were defined based on the existing MIEM CUs. Small adjustments were made after several meetings involving the UCs teaching staff, at various levels:

- Meetings between the CS and DEMec directors, and the coordinators of the disciplinary areas;

- Meetings between the coordinators of the disciplinary areas and teachers;

- Meetings between the CS director and teachers.

Those meetings led to the decision of adjusting the number of ECTS of each CU taking into account the CU specificities.

The LiEM is a broadband, non-professional CS, combining:

- Thorough training in the basic sciences, namely in mathematics, physics and technical drawing, and comprehensive training in the major scientific areas of Mechanical Engineering, with particular emphasis on Solid and Structural Mechanics, Fluid Mechanics, Thermodynamics and Heat Transfer, Electricity and Automation, Materials and Technological Processes, and Production Management;

- Significant laboratory/experimental and computational components; 
Reformulation of the Integrated Master in Mechanical Engineering (MIEM) at FEUP in Two Cycles of Studies (Bachelor and Master) L. F. M. da Silva, Jorge Seabra, António M. Lopes

- Personal development and transversal skills;

- Integrative Project.

The typology of the classes in most LiEM CUs includes:

- Theoretical-practical classes for a maximum of 60 students;

- Practical and laboratory classes for up to 20 students.

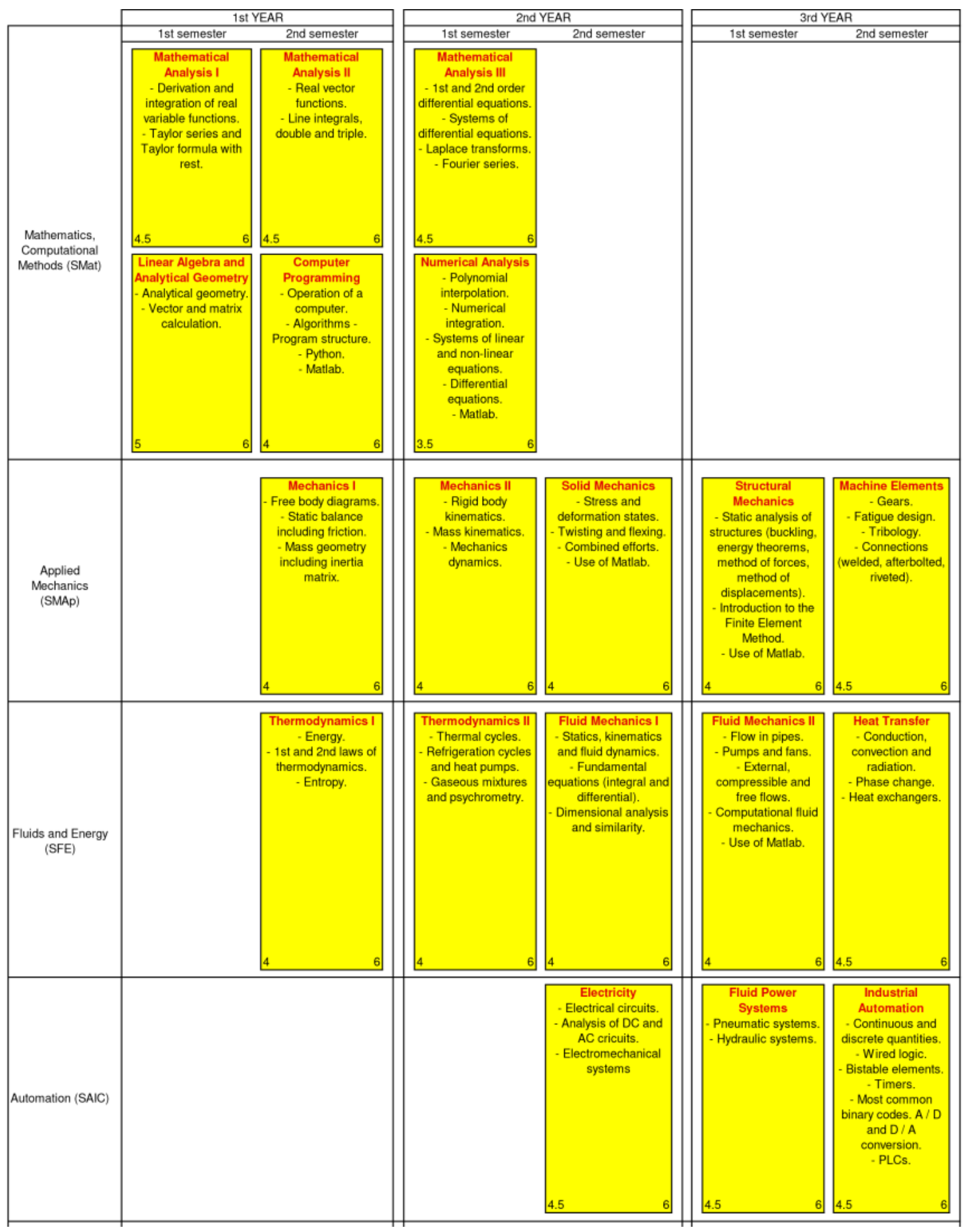

Figure 1: The LiEM structure 


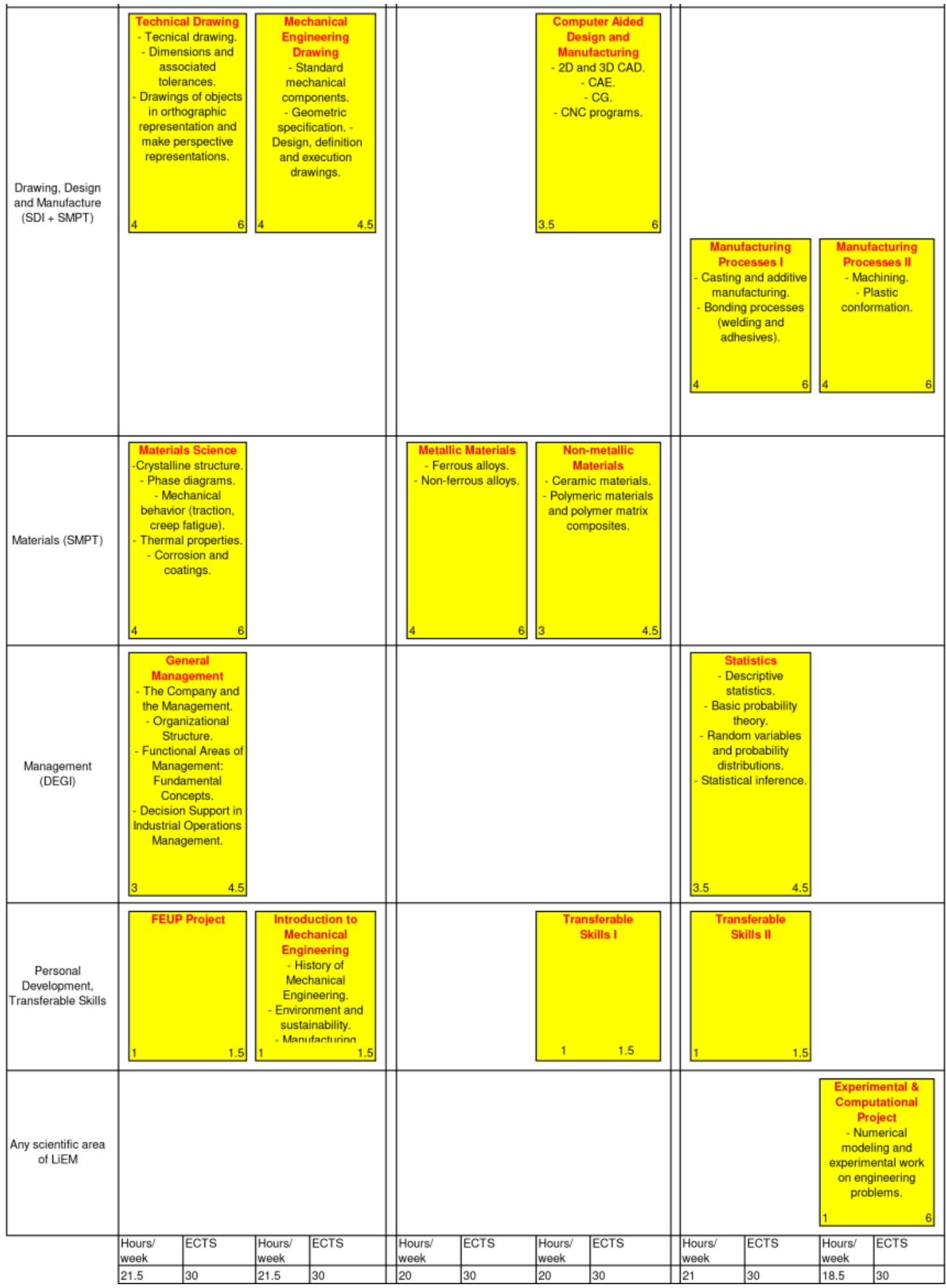

Figure 2: The LiEM structure (cont.)

The LiEM learning assessment will favor a mixed method, combining a final exam with a weighted distributed assessment component, or even just a distributed assessment. Thus, scientific learning will be assessed mainly via an individual written exam or mini-test. Technical learning, experimentation, design, interpretation of results and interpersonal relationships will mainly be assessed in assignments or projects (performed individually or in group), carried out during the duration of the CU. Communication skills will be assessed through reports and presentations. 
Many organizational and working procedures currently adopted in the MIEM will be maintained in the LiEM. For example, the teachers will plan the CUs and, at the beginning of each academic year, will make the plan available at the information system of FEUP (SIGARRA). All activities (i.e., classes, assignments, self-study, assessment tests, etc.) as well as an estimate of their associated workload must be indicated. Every year, at the beginning of each semester, a meeting between the CS director and the CUs teachers will occur, with the aim of distributing the workload required by the CUs, while avoiding work overload. After verification and adjustment, the CU plans are validated by the CS director. Midway through the semester, there will be a Monitoring Committee meeting to analyze the functioning of the CS. At the end of the semester, the teachers will prepare in SIGARRA a report on the operation of each CU, indicating the adequacy to the required work and the results obtained. Students will be surveyed via SIGARRA, and will express their views on the work required by the CUs. Students will also be heard via the Monitoring Committee and year representatives.

The LiEM teachers will be periodically evaluated according to the UP and FEUP performance appraisal regime. In addition, other evaluation mechanisms that have proven to work well in the current MIEM will be used.

\subsection{LIEM SWOT analysis}

The strengths, weaknesses, opportunities and threats of LiEM are listed in the follow-up.

\section{Strengths}

- It incorporates the status of the current MIEM and FEUP, which is advantageous for attracting the best students;

- It is a non-professional CS, providing a solid background in basic sciences and working as a "preparation" for pursuing second level CS, making it distinct from the CS thought at the polytechnic schools;

- It has teachers, mainly doctors, in exclusively, and integrated in R\&D Units of excellence;

- It has a good students/teachers ratio, ensuring its economic sustainability;

- It is designed and structured in line with the best practices adopted in European top universities;

- It includes a semester coordination mechanism, organized by academic years;

- It is supported by efficient technical services and by a good information system;

- It has access to adequate physical resources such as rooms, laboratories, computer resources and library;

- It can use a set of quality sensors/indicators provided by FEUP that can help in decision making processes;

- It can use FEUP's mechanisms for students' integration, pedagogical support and students' counseling.

\section{Weaknesses}

- The average age of the teachers is high;

- Some teachers are demotivated and unavailability for certain tasks, due to promotion bottlenecks;

- Few teachers attend training courses;

- The mobility of teachers is reduced;

- There is no systematic assessment of the effectiveness and impact of teacher education on their effective performance; 
- The large number of enrolled students creates difficulties in following them;

- There is little students' awareness of technology-based aspects of innovation and entrepreneurship, as well as social and professional aspects.

\section{Opportunities}

- Can attract many national and international students, taking advantage of the prestige of FEUP and the current MIEM, particularly as regards the employability of graduates;

- May attract students who want to pursue their studies by enrolling in the M.EM, designed to cover emerging areas of Mechanical Engineering, such as aeronautical and engineering structures of vehicles;

- Partnerships with foreign universities are an opportunity to significantly increase the mobility of LiEM teachers and students;

- The replacement of faculty members may allow for the diversification and lowering their average age;

- The effort in developing soft skills will enable students to acquire the relational skills they need;

- Enhanced laboratory teaching and programming can improve student preparation;

- Various extracurricular activities, some technological and cultural in nature, help to promote the development of students' skills.

\section{Threats}

- Students who, at the end of LiEM, want to enter the job market may find it difficult because LiEM is a non-professional CS;

- There is a non-negligible risk of losing students to other schools and to the job market;

- Teachers' performance assessment rules may impact negatively on their availability to perform teaching and management tasks;

- The size of the CS may affect its form of organization and its functioning.

\section{The Master Degree (M.EM)}

The M.EM is structured in 4 semesters, totalizing 120 ECTS:

- The approval in a set of CUs totalizing 90 ECTS corresponds to a non-awarding master diploma in Mechanical Engineering in one of 7 specialization areas: Machine Design, Aeronautical and Vehicle Structures, Fluids and Energy, Automation, Manufacturing, Production Engineering \& Management, and General Mechanical Engineering;

- The approval in a dissertation of original scientific nature with 30 ECTS awards students with the Master degree in Mechanical Engineering in one of the 7 aforementioned specializations.

The 120 ECTS ensure that students acquire an academic specialization through research and innovation, meeting the needs of the industry, both in emerging mechanical engineering and in areas with strong research activity in DEMec, accompanying the installation in the north of Portugal of many development centers and production units of various national and international companies.

\subsection{M.EM organization}

The M.EM offers knowledge, methods and techniques in areas of Mechanical Engineering, such as construction and maintenance of equipment, energy production and management, production planning and management, automation, development and application of new materials, and development of new products. It promotes experience in the use of computer 
and communication technologies, skills in the use of scientific computing, databases and management, CAD/CAM/CAE systems, and computer applications for automation. It will prepare the students so that, throughout life and independently, they can use their technical and scientific knowledge to solve problems, recognize the need for experimentation and be able to design, perform and interpret results, communicate and interact with a wide range of audiences and through various media, be able to participate in multidisciplinary teams with personal integrity and professional ethics, and can develop their own training.

The M.EM is a rigorous and demanding CS, different from others CS in the same area. The teaching language will be English, to open the CS to international students and to develop this skill with Portuguese students.

When compared with the MIEM, the number of specializations is increase from 5 to 7 . This will allow effective laboratory classes and high teacher/student interaction. This last point is very important, since the number of contact hours in the M.EM will be small (only 3 hours/week per CU).

The specializations will be more adapted to the needs of the industry, to emerging technological areas of mechanics, and to areas with strong research at DEMec. This will transfer to the M.EM the scientific excellence of DEMec, differentiating and valuing the CS in relation to the competition.

It is expected that the industry and the society in general will look at the M.EM as a reference CS that trains top professionals who make a difference in the company. A new specialization in an area with a strong economic presence in Portugal, the area of transports will be created. Its will focus on the aeronautical area, but intends to train engineers able to design any transport structure (e.g., automobile and railroad). The experience that will be acquired with such specialization may be used to create an independent master in aeronautics in the future. A specialization of a transversal nature is included (General Mechanical Engineering) because in many cases the industry needs professionals with general knowledge. It is a practice followed in many reference universities. This specialization is entirely composed of CUs from the other specializations.

Elective CUs, one in the second plus one in the third semesters, are included, which can be CU from other specializations of the M.EM, from other FEUP CS, or from other UP CS. Therefore, the students have the possibility to freely choose a transversal competence of 1.5 ECTS plus $2 \times 6$ ECTS.

Figure 3 portraits the structure designed for the M.EM. The first 3 semesters include 5 mandatory CUs. In the first and second semesters, the M.EM has general CUs in the main areas of Mechanical Engineering. In the second and third semesters it comprises several CUs in the specific area of specialization (Machine Design, Aeronautical and Vehicle Structures, Fluids and Energy, Automation, Manufacturing, Production Engineering \& Management, and General Mechanical Engineering). The fourth semester is devoted to the dissertation. In the first 3 semesters the students are free to choose one sixth CUs.

The ECTS of each CU, the typology of the classes and the most working procedures are as described for the LiEM. 


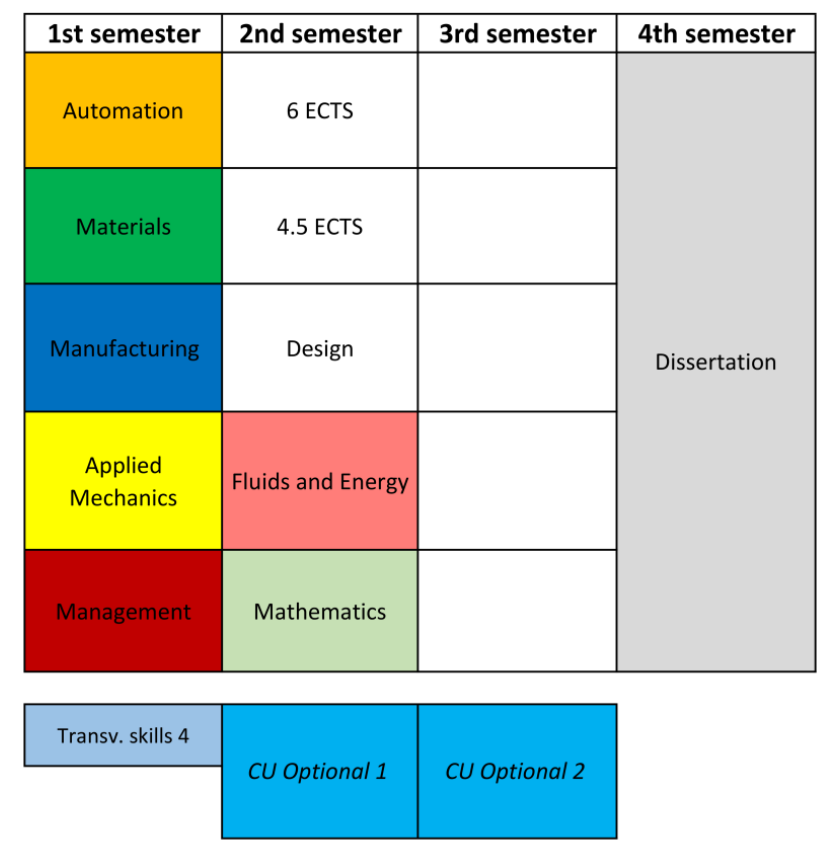

Figure 3: The M.EM structure

\subsection{M.EM SWOT analysis}

The strengths, weaknesses, opportunities and threats of M.EM are listed in the follow-up. Some are common to those of the LiEM.

\section{Strengths}

- It benefits from the prestige of the MIEM and FEUP;

- It covers all major areas of traditional Mechanical Engineering and several emerging areas, aligned with the industry needs and valuing the research of excellence carried out at DEMec;

- It has a good student to teacher ratio, ensuring its economic sustainability;

- Its structure is well defined and in line with those adopted by European top universities;

- It has a semester coordination mechanism organized by academic years;

- It is backed up by efficient technical services and a quality information system;

- It uses adequate physical means, such as rooms, laboratories, computer resources, and library;

- Most teachers are doctors, in exclusively, and are integrated in R\&D Units of excellence;

- FEUP implements a set of quality sensors/indicators that are used for decision making, and those can be adopted by the CS;

- At FEUP, there are efficient mechanisms for integration, pedagogical support and student counseling, and those can be adopted by the CS.

\section{Weaknesses}

- The average age of the teachers is high;

- Few opportunities for promotion have negative impact on the availability of teachers for certain tasks;

- The mobility of teachers is reduced;

- Few teachers attend training courses; 
- There is no systematic assessment of the effectiveness and impact of the teachers' education on their effective performance;

- The size of the CS creates difficulties in following all students.

\section{Opportunities}

- It may attract many students from other national and international schools;

- The introduction of emerging areas of Mechanical Engineering, such as aeronautical and vehicle structures, can attract motivated students;

- Partnerships with foreign universities are an opportunity to significantly increase the mobility of the teachers and students;

- The effort to develop soft skills will enable students to acquire the relational skills they need;

- The existence of a variety of extracurricular activities, some technological and cultural in nature, help to promote the development of students' capacities;

- There are new opportunities to increase contact with employers, such as the FEUP FIRST JOB initiative. Moreover, the UPTEC (University of Porto Science and Technology Park) and UPIN (University of Porto Innovation) can help the employability of the graduates.

\section{Threats}

- There is a risk of losing students who, at the end of their bachelor, may want to enroll in a CS at other university, or enter in the job market;

- The transition from the LiEM to the M.EM is not defined;

- The type of funding the Portuguese Government will apply to the second level CS may leave out potential students, due to economic difficulties;

- The number of specializations can lead to difficulties in selecting/placing candidates, and some may refuse placement in "narrow spectrum" specializations if they do not match their preferred selection;

- The high number of specializations can difficult the employers' perception about the transversality of the CS;

- The size of the SC may affect its form of organization and its functioning.

\section{Conclusions}

This paper presented the reformulation of MIEM in two independent first and second CS: the bachelor (LiEM) and the master (M.EM). The most sensible decision was to adopt the scheme $3+2$ years for the new CS. The decision took place at FEUP's level, with the rationale of being a solution close to the practice at FEUP with the integrated masters. Therefore, maintaining a "product" that had proven effective in the job market and in line with the good European higher education schools.

The design of the LiEM was the biggest challenge. It should be understood as a nonprofessional CS of preparation for the M.EM. It is clearly distinct from the CS thought at the polytechnic schools, providing a broader scientific background, and not including design skills and dissertation.

The M.EM is a very rigorous and demanding CS, differentiated from what is practiced in Portugal, designed to attract undergraduate students from other Portuguese and foreign CS. This is achieved fundamentally with innovative content, aligned with the needs of the industry and the value added by the scientific research carried out at DEMec. 


\section{References}

Choe, N. H., L. L. Martins, M. Borrego, and M. R. Kendall. 2019. "Professional aspects of engineering: Improving prediction of undergraduates' engineering identity". Journal of Professional Issues in Engineering Education and Practice 145, no. 3: 04019006. https://doi.org/10.1061/(Asce)Ei.1943-5541.0000413.

Fink, F. K. 1999. "Integration of engineering practice into curriculum-25 years of experience with problem based learning". In FIE'99 Frontiers in Education. 29th Annual Frontiers in Education Conference. Designing the future of science and engineering education. Conference Proceedings, 11A2/7-11A212. https://doi.org/10.1109/FIE.1999.839084.

Heitmann, G. 2005. "Challenges of engineering education and curriculum development in the context of the Bologna process". European Journal of Engineering Education 30, no. 4: 44758. https://doi.org/10.1080/03043790500213136.

Jimenez, G., J. J. Pardo, E. Minguez, and D. Cuervo. 2015. "Educational initiatives to develop transversal skills in the nuclear engineering subjects at Universidad Politecnica de Madrid". The International Journal of Engineering Education 31, no. 1: 229-37. https://doi.org/10.1080/03043790500213136.

Mesquita, D., R. Lima, R. Sousa, and M. Flores. 2009. "The connection between project learning approaches and the industrial demand for transversal competencies". In Proceedings of the 2nd International Research Symposium on PBL (IRSPBL'2009), 1-8.

Palmer, S. 2004. "Authenticity in assessment: Reflecting undergraduate study and professional practice". European Journal of Engineering Education 29, no. 2: 193-202. https://doi.org/10.1080/03043790310001633179.

Shamshina, I. G. 2014. "Professional competences necessary for the bachelor-degree-holding engineer specialising in engineering industries". Pacific Science Review 16, no. 2: 85-88. https://doi.org/10.1016/j.pscr.2014.08.018.

Sun, R. S., and X. Z. Xue. 2010. "Improve the quality of undergraduate teaching by introducing scientific research mode". Journal of Higher Education in Science \& Technology 12: 99-100.

Teixeira, J. C., J. Ferreira da Silva, and P. Flores. 2007. "Development of mechanical engineering curricula at the University of Minho". European Journal of Engineering Education 32, no. 5: 539-49. https://doi.org/10.1080/03043790701433210.

Wächter, B. 2004. "The Bologna Process: Developments and prospects". European Journal of Education 39, no. 3: 265-73. https://doi.org/10.1111/j.1465-3435.2004.00182.x. 